\title{
Quercetin Supplementation Ameliorates Myopathy Associated with Induced Type 2 Diabetes Mellitus in Rats
}

\author{
SOHEIR A. SALEH, M.D.*; MOHAMED HANAFY, M.D.*; SUZY F. EWIDA, M.D.*; \\ MOHAMED A. ZAYED, M.D.**** and SUZAN A.A. KHODIR, M.Sc.* \\ The Department of Physiology, Faculty of Medicine, Menoufia University, Egypt* and Rabigh Branch, King Abdul Aziz University, \\ Saudi Arabia**
}

\begin{abstract}
Background: Myopathy is a common associated diabetic complication due to hyperglycemia and insulin resistance. Quercetin acts as reactive oxygen species' scavenger and peroxidation reactions' suppressor which causes development of diabetic complications.
\end{abstract}

Aim of Study: We investigated the possible improving effect quercetin on glycemic state, insulin resistance \& skeletal muscle performance in type 2 diabetic male rats and tried to elucidate the possible underlying mechanisms.

Patients and Methods: Thirty rats were randomly divided into three groups; non-diabetic, diabetic non-treated \& quercetin treated groups. Type 2 diabetes mellitus was induced by adding $10 \%$ fructose for 2 weeks followed by single intraperitoneal injection of streptozotocin as a consequence of hyperglycemic insulin resistance. Quercetin was given in a dose of $50 \mathrm{mg} / \mathrm{kg}$ body weight orally for 4 weeks. After the end of the 4-week experimental period, fasting serum glucose, glycosylated hemoglobin, fasting serum insulin, HOMA-IR index, serum TNF- $\alpha$, MDA, total antioxidant capacity, Gast $\mathrm{wt} / \mathrm{Tib} \mathrm{L}$ ratio, the strength of muscle contraction at the start and after 30 min activity \& glucose uptake by the muscle during 30min activity and after 30min recovery were assessed.

Results: Fructose \& Streptozotocin administration significantly increased fasting serum glucose, glycosylated hemoglobin (HbA1C), fasting serum insulin, HOMA IR index, confirming successful establishment of Type 2 diabetes Mellitus model. Also increased serum MDA, TNF- $\alpha$ and decreased total antioxidant capacity associated with decreased Gast wt/ Tib $\mathrm{L}$ ratio, decreased the strength of muscle contraction at the start and after 30min activity and reduced glucose uptake by the muscle during 30min activity and after $3 \mathrm{~min}$ recovery indicating occurrence of myopathy. Quercetin supplementation significantly improved the previously measured parameters compared to diabetic non-treated group.

Conclusion: Quercetin improving effect against myopathy complicating induced type 2 diabetes mellitus may be linked to its antioxidant and anti-inflammatory effect with reduced hyperglycemia and insulin resistance.

Correspondence to: Dr. Suzy F. Ewida, E-Mail: suzy.ewida@med.menofia.edu.eg
Key Words: Quercetin-Fructose-Streptozotocin - Type 2 diabetes -Anti-inflammatory -Antioxidant.

\section{Introduction}

DIABETES Mellitus (DM) is a metabolic disease characterized by chronic hyperglycemia due to insulin deficiency, resistance, or both. Diabetic complications affect patients' quality of life with changes in morbidity and mortality result in major health costs [1]. The core pathophysiological feature in type 2 diabetes mellitus is insulin resistance, with increased hepatic glucose production and decreased glucose uptake leading to chronic hyperglycemia; a clinical hallmark of diabetes mellitus [2].

Myopathy is a common associated diabetic complication due to hyperglycemia and insulin resistance. Myopathy characterized by loss of muscle mass and strength with a reduction in vitality, poor mobility and physical function [1] Because of the key role of skeletal muscle on locomotion and glucose homeostasis, it is believed that myopathy contributes to the progression of additional diabetic complications [3].

Diabetes mellitus is associated with oxidative stress which is due to overproduction of reactive

\begin{tabular}{ll}
\hline Abbreviations: & \\
ANOVA & $:$ Analysis of Variance. \\
DM & : Diabetes Mellitus. \\
Gast wt/Tib L & Gastrocnemius Weight to Tibial Length Ratio. \\
GLUT4 & Glucose Transporter 4. \\
HbA1C & $:$ Glycosylated Hemoglobin A1C. \\
HOMA-IR & $:$ Homeostatic Model Assessment Insulin \\
& Resistance Index. \\
MDA & $:$ Malondialdehyde. \\
rpm & Rotation per minute. \\
STZ & $:$ Streptozotocin. \\
TNF- $\alpha$ & $:$ Tumor necrosis factor-alpha.
\end{tabular}


oxygen species as well as a significant reduction in antioxidant defense system, participating in evolution of insulin resistance and diabetic complications [4]. Inflammatory processes also are also involved in the progression of diabetes and the development of diabetic complications [5].

Quercetin, abundant in apples, onions and tea, is a powerful antioxidant that has the potential to improve insulin action [6]. Quercetin acts as reactive oxygen species' scavenger and peroxidation reactions' suppressor, exhibits a broad range of pharmacological activities such as anti-inflammatory, anti-oxidant, anti-tumor \& immunomodulatory. So it may be helpful in prevention and management of many conditions such as diabetes [7].

The aim of the present investigation was to study the possible improving effect quercetin on glycemic state, insulin resistance \& skeletal muscle performance in type 2 diabetic male rats and to elucidate the possible underlying mechanisms.

\section{Material and Methods}

This study was conducted at Physiology Department during study period of Jun. 2016 to October 2017.

Chemicals: D-Fructose (Technogene Company, Egypt), Streptozotocin (Sigma Chemical Company, USA), Quercetin (Sigma Chemical Company India), Chemicals used for preparation of Krebs solution (Altogaria, Company, Egypt). Kits for estimation of glucose in the bathing solution \& serum (Biodiagnostic Company, Egypt), Kits for estimation of glycosylated hemoglobin (stanbio glycohemoglobin, Egypt), Kits for estimation of insulin (DRG Instruments GmbH, Germany), Kits for estimation of serum TNFot (Assaypro company, U.S.A.), Kits for estimation of total antioxidant capacity (Bio-diagnostic Company, Egypt), Kits for estimation of MDA (Bio Diagnostic Company, Egypt).

\section{Animals and experimental design:}

This study was conducted in accordance with the regulations of Animal Experimentation Ethics Committee of Faculty of Medicine Menoufia University. Thirty adult male albino rats of local strain, weighing 120-150 grams each were used. Rats were housed in standard conditions with a natural light-dark cycle and were caged in a wire mesh ventilated cages with free access to food and water throughout the study period. Rats were divided equally into the following three experimental groups $(n=10)$ as follows:
I- Non-diabetic group: Normal rats with fasting blood glucose level less than $110 \mathrm{mg} / \mathrm{dl}$ were given standard rat chow diet and water ad libitum.

II-Diabetic non-treated group:Type 2 diabetes was induced by adding $10 \%$ fructose in drinking water ad libitum for two weeks. After two weeks of dietary manipulation, this group received a single intraperitoneal injection of Streptozotocin (STZ) $(40 \mathrm{mg} / \mathrm{kg}$ b.w.) dissolved in $0.2 \mathrm{ml}$ of 10 $\mathrm{mmol} / \mathrm{l}$ citrate buffer $(\mathrm{pH} 5.5) \quad[8] .0 .5 \mathrm{ml}$ dextrose $5 \%$ was given intraperitoneally 30 minutes before STZ injection as a protective dose and rats were supplied with sucrose in the drinking water $(10 \%)$ to avoid sudden hypoglycemia after injection [9]. Fasting blood samples were taken from rat tails after 2 days of streptozotocin administration. Rats with fasting blood glucose levels $>200 \mathrm{mg} / \mathrm{dl}$ were considered diabetic [10]. Rats of this group were given standard rat chow diet and water ad libitum $\&$ were left for 4 weeks.

III- Diabetic quercetin-treated group:Diabetic rats were given quercetin in a dose of $50 \mathrm{mg} / \mathrm{kg}$ body weight orally for 4 weeks. The drug was dissolved in distilled water and was given orally by gavage [11]

At the end of the experimental period (4 weeks), rats were fasted overnight and blood samples were collected from the retro-orbital venous plexus from each rat using a fine heparinized capillary tube. 4 milliliters of blood were taken \& divided into 2 tubes equally. The first tube was left for clotting at room temperature in a water bath for 10 minutes, and then centrifuged at 4000 rotation per minute (r.p.m.) for 10 minutes. Serum was frozen at -20 until needed for subsequent analysis. The second tube, blood was collected into EDTA tube, this fraction was used for estimation of Glycosylated hemoglobin ( $\mathrm{HbA} 1 \mathrm{c})$. Lastly, rats were sacrificed by cervical dislocation and hemi-diaphragm sample was prepared according to the method Bülbring and Chou [12] for in vitro skeletal muscle performance assessment.

In vitro skeletal muscle performance assessment [12]: The hemi-diaphragm preparation was placed in organ bath \& mounted to isometric transducer connected to the 4 channel oscillograph (Harvard, UK). Direct repetitive stimulation (2 impulse/sec) of the hemi-diaphragm sample was done for 30 minutes. Strength of muscle contraction was measured at the start $\&$ after 30 minutes of activity of prepared strip. Glucose uptake by muscle during 30 minutes activity \& 30 minutes recovery was done by taking samples from the bathing solution. 
After that gastrocnemius muscle was dissected from its bone attachment \& weighed. The tibia was freed from the surrounding tissues. Gastrocnemius weight per unit of tibial length (Gast wt/ Tib L) was calculated [13]

\section{Techniques of biochemical analysis:}

Estimation of glucose level [14]:

Fasting blood glucose level (FBG) (mg/dl) was determined colorimetrically using a test reagent kit after being oxidized enzymatically to yield a red violet quinoneimine.

Estimation of Glycosylated hemoglobin ( $\mathrm{HbAl} \mathrm{c}$ ) [15]: It was estimated by using kit reagent. We measured the ratio of absorbance values of the $\mathrm{HbA} 1$ and of the total $\mathrm{Hb}$ at $415 \mathrm{~nm}$ in a prepared hemolyzed blood sample mixed with a weakly binding cation-exchange resin.

Estimation of Insulin levels and determination of insulin resistance [16]: Insulin level ( $\mathrm{U} / \mathbf{n} \mathbf{l})$ was measured using solid phase Enzyme-Linked Immunosorbent Assay (Elisa) based on the sandwich principle.

Homeostasis Model Assessment index (HOMA$I R)$ : Insulin resistance was estimated by homeostasis model assessment index (HOMA-IR): Insulin ( N/nal) X glucose $(\mathrm{mg} / \mathrm{dl}) \div 405$.

Estimation of serum tumour necrosis factor alpha $(T N F \alpha)$ [17]: The determination of TNF $\alpha$ by ELISA kits depends on monoclonal antibody specific for TNF- $\alpha$ coated into microplate with removable strips.

Estimation of Total Antioxidant Capacity (TAC) [18]: The determination of the anti-oxidative capacity is performed by the reaction of antioxidants in the sample with a defined amount of $\mathrm{H}_{2} \mathrm{O} 2$ with measuring the residual ${ }_{\mathrm{H} 2 \mathrm{O} 2}$ calorimetrically by an enzymatic reaction, which involves the conversion of 3,5 dichloro-2-hydroxy benzenesulphonate to a colored product.

Estimation of serum MDA [19]: Estimation of Malondialdehyde (MDA) was done by assessing thiobarbituric acid reactive products, as oxidative stress markers measuring the peroxidation of fatty acids by using test reagent kits.

\section{Statistical analysis:}

The data were tabulated and analyzed by SPSS (statistical package for the social science software) using statistical package Version 20 on IBM compatible computer. Quantitative data were expressed as mean \pm standard error of mean (X \pm S.E.M).
Data from control and test groups were compared using one way ANOVA, followed by Turkey post Hoc test, probability value of less than 0.05 was considered as statistically significant $(p<0.05)$.

\section{Results}

Serum biochemical analysis:

Fasting serum glucose, glycosylated hemoglobin (HbA1C) and HOMA-IR in diabetic non-treated group were significantly higher $(p<0.05)$ compared to their corresponding levels in non-diabetic group, while these parameters in diabetic quercetin-treated were significantly lower $(p<0.05)$ compared to their corresponding levels in diabetic non-treated group.

Fasting serum insulin level in diabetic nontreated and diabetic quercetin-treated groups were significantly higher $(p<0.05)$ compared to their corresponding levels in non-diabetic group (Table 1).

Serum MDA and TNF- $\alpha$ in non-diabetic group were significantly higher $(p<0.05)$ in diabetic nontreated group compared to their corresponding levels in non-diabetic group, while these parameters in diabetic quercetin-treated were significantly lower $(p<0.05)$ compared to their corresponding levels in diabetic non-treated group (Table 1).

Serum total antioxidant capacity of diabetic non-treated group was significantly lower $(p<0.05)$ compared to their corresponding level in nondiabetic group, while this parameter in diabetic quercetin-treated was significantly higher $(p<0.05)$ compared to their corresponding level in diabetic non-treated group (Table 1).

\section{In vitro skeletal muscle performance:}

The ratio of gastrocnemius weight to tibial length in $\mathrm{gm} / \mathrm{cm}$ of diabetic non-treated group was significantly lower $(p<0.05)$ compared to their corresponding level in non-diabetic group, while this parameter in diabetic quercetin-treated was significantly higher $(p<0.05)$ compared to their corresponding level in diabetic non-treated group (Table 2).

Glucose uptake by diaphragm after 30min activity and after $30 \mathrm{~min}$ recovery in diabetic nontreated group were significantly lower $(p<0.05)$ compared to their corresponding levels in nondiabetic group, while these parameters in diabetic quercetin-treated were significantly higher $(p<0.05)$ compared to their corresponding levels in diabetic non-treated group (Table 2). 
Table (1): Serum glucose, glycosylated hemoglobin (HbA1C), insulin, HOMA-IR, MDA, Serum total antioxidant capacity and TNF- $\alpha$ level in non-diabetic, diabetic non-treated and diabetic quercetin-treated groups.

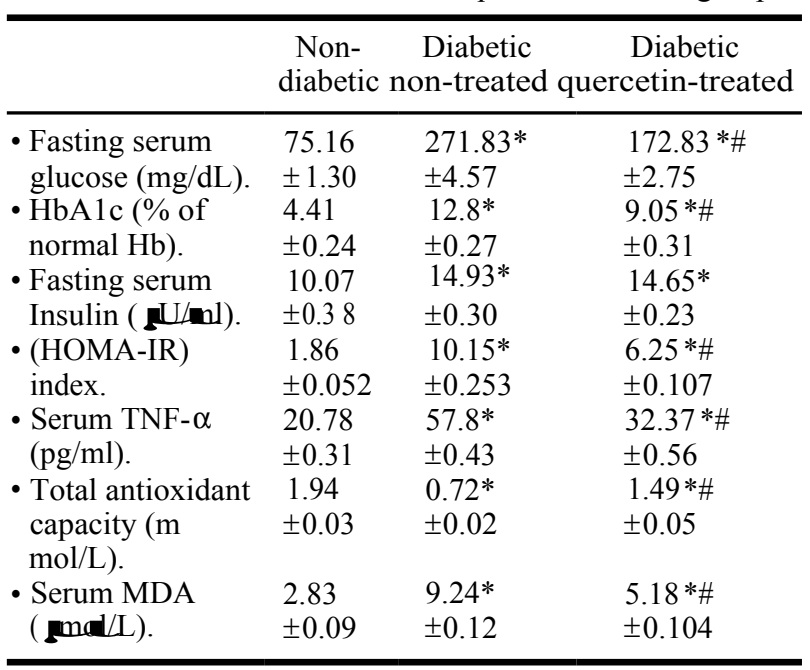

Data were expressed as mean \pm S.E. $(n=10)$.

One way ANOVA: ${ }^{*} p<0.05$, vs non-diabetic.

$\#: p<0.05$, vs. diabetic non-treated group.

Strength of contraction of diaphragm at the start and after thirty minutes of activity in diabetic non-treated group were significantly lower $(p<0.05)$ compared to their corresponding levels in non-
Table (2): Ratio of gastrocnemius weight /tibial length $(\mathrm{gm} / \mathrm{cm})$, glucose uptake by diaphragm ( $\mathrm{mg} / \mathrm{g}$ tissue) after $30 \mathrm{~min}$ activity $\&$ after $30 \mathrm{~min}$ of recovery in nondiabetic, diabetic non-treated and diabetic quercetintreated groups.

\begin{tabular}{llll}
\hline & $\begin{array}{c}\text { Non- } \\
\text { diabetic }\end{array}$ & $\begin{array}{c}\text { Diabetic } \\
\text { non-treated quercetin-treated }\end{array}$ \\
\hline - Ratio of & 0.93 & $0.65^{*}$ & $0.75^{* \#}$ \\
gastrocnemius & \pm 0.006 & \pm 0.011 & \pm 0.009 \\
$\begin{array}{l}\text { weight/tibial } \\
\text { length (gm/cm) }\end{array}$ & & & \\
- Glucose uptake & 6.02 & $1.94^{*}$ & $3.43^{* \#}$ \\
$\begin{array}{l}\text { by diaphragm } \\
\text { (mg/g tissue) after }\end{array}$ & \pm 0.21 & \pm 0.13 & \pm 0.09 \\
$\begin{array}{l}\text { 30min activity } \\
\text { Glucose uptake }\end{array}$ & 4.72 & $1.58^{*}$ & \\
by diaphragm & \pm 0.23 & \pm 0.08 & \pm 0.06 \\
(mg/g tissue) after & & & \\
$\begin{array}{l}\text { 30min of } \\
\text { recovery }\end{array}$ & & & \\
\hline
\end{tabular}

Data were expressed as mean \pm S.E. $(n=10)$.

One way ANOVA: $* p<0.05$, vs non-diabetic.

$\#: p<0.05$, vs. diabetic non-treated group.

diabetic group, while these parameters in diabetic quercetin-treated were significantly higher $(p<0.05)$ compared to their corresponding levels in diabetic non-treated group Fig. (1).
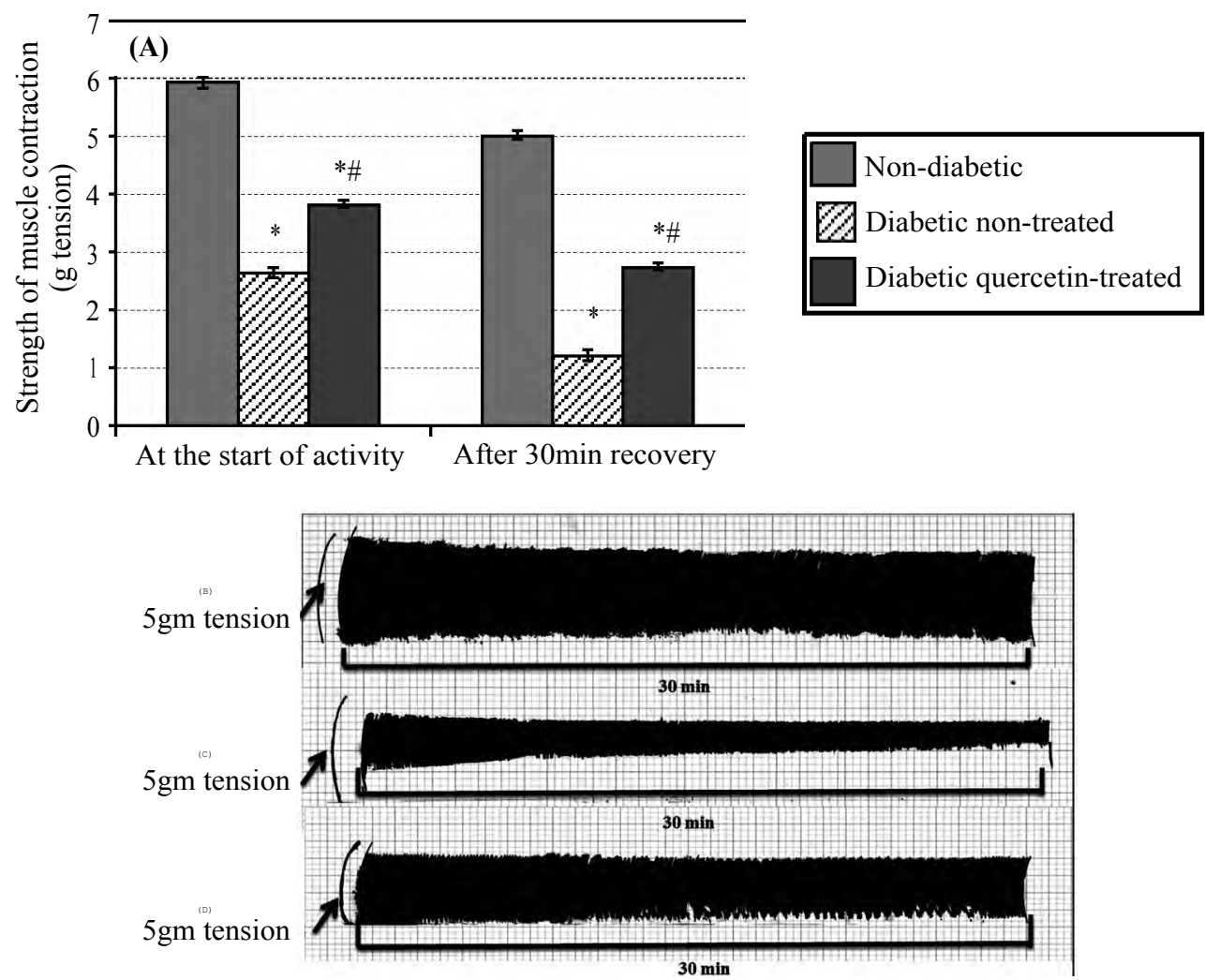

Fig. (1): (A) Strength of contraction of hemi-diaphragm (g tension) at the start and after 30min activity of repeated direct electrical stimulation (2 impulse/sec) in all experimental groups. (B) Non-diabetic, (C) Diabetic non-treated, (D) Diabetic quercetin-treated.

Data were expressed as mean \pm S.E. $(n=6-8)$. One way ANOVA: ${ }^{*} p<0.05$, vs. non-diabetic. $\not \neq p<0.05$, vs. diabetic non-treated group. 


\section{Discussion}

Diabetic myopathy is a relatively understudied complication of diabetes mellitus, but is believed to directly influence the rate of development of associated morbidity [20]. The muscle becomes functionally impaired as demonstrated by a decline in muscle strength [21,22], and "metabolically inflexible" as switching between fat and carbohydrate oxidation in response to insulin can't occur easily [23]

In the present investigation, type 2 diabetes mellitus complicated with myopathy was successfully established by adding 10\% fructose for 2 weeks followed by single intraperitoneal injection of Streptozotocin (STZ), as evidenced by; significant increase in fasting serum glucose, glycosylated Hemoglobin (HbA1C), fasting serum insulin and HOMA IR index. While Gast wt/Tib L ratio, the strength of muscle contraction at the start and after 30 min activity \& glucose uptake by the muscle during $30 \mathrm{~min}$ activity and after $30 \mathrm{~min}$ recovery were significantly lower in type 2 diabetic nontreated group when compared to the corresponding values of non-diabetic group.

The developed insulin resistance evidenced by significant increase in fasting serum glucose, glycosylated hemoglobin (HbA1C), fasting serum insulin and HOMA IR index in diabetic non-treated group in the present investigation was induced by adding $10 \%$ fructose in drinking water ad libitum, respectively for two weeks [8]. Fructose loads have been found to decrease the number of insulin receptors, and subsequent insulin resistance [24] It may also induce skeletal muscle insulin resistance [25]. The associated hyperinsulinemia may be explained by Wilson \& Islam [8] as fructose minimizes the oxidative damage on pancreatic b-cells when concomitantly given with Streptozotocin better than the oxidative stress that would be produced by the individual agents alone.

Diabetic myopathy characterized by reduced muscle size, function and metabolism was evidenced in this investigation by the reduced Gast wt/ Tib L ratio, the strength of muscle contraction at the start and after $30 \mathrm{~min}$ activity \& glucose uptake by the muscle during $30 \mathrm{~min}$ activity and after 30min recovery. The reduction of strength of muscle contraction \& its glucose uptake of diabetic non-treated group can be explained by insulin resistance in striated muscle. This insulin resistance possibly induced by generation of inflammatory mediators [26]. TNF- $\alpha$ is a key marker of inflammation whose expression is unregulated in the adipose tissue and/or skeletal muscle of both obese insulin resistant human subjects and experimental animal models [27]. Fernandez-Real \& Pickup [28] reported that TNF- $\alpha$ induces insulin resistance by down-regulating the insulin signaling cascade.

The statistically significant increase in MDA level \& decrease in antioxidant enzymes also play an important role in the development of insulin resistance and may be induced by hyperglycemia. Various consequences of oxidative stress in diabetic subjects involve accumulation of malondialdehyde [29]. The skeletal muscles of the diabetic group suffer from damaging effects of the ROS and this leads to decline in their contractile functions.

Treatment of diabetic rats with quercetin (50 $\mathrm{mg} / \mathrm{kg} \mathrm{B.W}$.) daily for 4 weeks, revealed statistical significant reduction of fasting serum glucose, glycosylated hemoglobin (HbA1C), HOMA IR index denoting improvement of hyperglycemia and insulin resistance.

Quercetin is one of the most potent antioxidants effective in reducing reactive oxygen species in vitro and in vivo [30]. The hypoglycemic effect of quercetin may be due to its antioxidant property [31]; this was proved by statistically significant elevation in the total antioxidant capacity \& statistically significant decrease in MDA level of quercetin-treated group when compared to the corresponding values of diabetic non-treated group seen in the present investigation.

Regarding serum insulin level the result of the present investigation were in agreement with Saad et al., [32], who reported that by the end of the treatment period, all diabetic groups (untreated and treated) exhibited a significantly higher serum insulin levels despite the significant decline in the insulin resistance index.

Quercetin also improved the myopathy associated with type 2 diabetes as evidenced by; the significant increase in Gast wt/Tib L ratio, the invitro strength of contraction of diaphragm at the start and after 30min activity \& glucose uptake by the diaphragm after $30 \mathrm{~min}$ activity and $30 \mathrm{~min}$ recovery. Eid et al., [33] suggested that to improving glucose uptake by the muscle $\&$ adipose tissue through stimulating GLUT4 translocation and expression in skeletal muscle reduces the hyperglycemia. Quercetin stimulates GLUT4 translocation and expression in skeletal muscle, by mechanisms associated with the activation of AMP-Activated Protein Kinase (AMPK) rather than insulindependent pathways. 
The improved strength of skeletal muscle contraction in diabetic quercetin-treated group seen in the present investigation can be also explained by the anti-oxidant effect of quercetin. This was proved by the significant reduction of serum MDA level which is a lipid peroxidation marker \& significant elevation in the total antioxidant capacity of diabetic quercetin-treated group when compared to the corresponding values of diabetic non-treated group. Prochazkova et al., [34] revealed that the antioxidant properties of quercetin and other flavonoids compounds are thought to be particularly due to their scavenging ability.

The significant reduction of TNF- $a$ in quercetintreated group can explain the improvement in muscle strength and glucose uptake. Anhe et al., [6] found that improvement in insulin sensitivity has been reported by intraperitoneal administration of quercetin in mice, subsequently a reduction in inflammation was reported which was attributed to the insulin resistance. Beneficial effects of quercetin and its derivatives against inflammation, in vivo models suggest that it is a potent antiinflammatory agent. The reduction of TNF- a, the associated reduction in insulin resistance and the increased expression of GLUT4 in skeletal muscles [33], lead to increased glucose uptake hence improved strength of skeletal muscle contraction.

\section{Conclusion:}

Quercetin treatment improved the glycemic state as it decreased fasting serum glucose, glycosylated hemoglobin and decreased insulin resistance in diabetic rats. It improved also the strength of muscle contraction caused by direct repetitive electrical stimulation at the onset and after 30min activity and its glucose uptake during $30 \mathrm{~min}$. activity and after $30 \mathrm{~min}$. recovery in diabetic rats. This can be explained by several mechanisms among which the hypoglycemic, antioxidant and anti-inflammatory effects.

\section{Acknowledgements:}

Authors wish to thank Menoufia University for providing all required facilities.

\section{References}

1- HERNÁNDEZ-OCHOA E.O. and VANEGAS C.: Diabetic Myopathy and Mechanisms of Disease. Biochem. Pharmacol. (Los Angel) 4: e179. doi: 10.4172/21670501.1000e 179, 2015.

2- PALSAMY P., SIVAKUMAR S. and SUBRAMANIAN S.: Resveratrol attenuates hyperglycemia-mediated oxidative stress, proinflammatory cytokines and protects hepatocytes ultrastructure in streptozotocin nicotinamide- induced experimental diabetic rats. Chem. Biol. Interact., 186 (2): 200-10, 2010.

3- KAHN B.B., ROSEN A.S., BAK J.F., ANDERSEN P.H., DAMSBO P., et al.: Expression of GLUT1 and GLUT4 glucose transporters in skeletal muscle of humans with insulin-dependent diabetes mellitus: Regulatory effects of metabolic factors. J. Clin. Endocrinol. Metab., 7: 11019, 1992.

4- BRASNYÓ P., MOLNAR G.A., MOHAS M., MARKO L., LACZY B., CSEH J. MIKOLAS E., SZIJARTO I.A., MEREI A., HALMAI R., MESZAROS L.G., SUMEGI B. and WITTMANN I.: Resveratrol improves insulin sensitivity, reduces oxidative stress and activates the Akt pathway in type 2 diabetic patients. Br. J. Nutr., 106: 383 9, 2011.

5- DONATH M.Y. and SHOELSON S.E.: Type 2 diabetes as an inflammatory disease Nat. Rev. Immunol., 11: 98$107,2011$.

6- ANHE G.F., OKAMOTO M.M., KINOTE A., SOLLON C., LELLIS-SANTOS C., ANHE F.F., LIMA G.A., HIRABARA S.M., VELLOSO L.A., BORDIN S. and MACHADO: Quercetin decreases inflammatory response and increases insulin action in skeletal muscle of ob/ob mice and in L6 myotubes. Eur. J. Pharmacol., 689: 285-93, 2012.

7- MAHMOUD M.F., HASSAN N.A., EL-BASSOSSY H.M and FAHMY A.: Quercetin Protects against DiabetesInduced Exaggerated Vasoconstriction in Rats: Effect on Low Grade Inflammation. PLoS ONE, 8 (5): e63784. Doi: 10.1371/journal.pone.0063784, 2013.

8- WILSON R.D. and ISLAM M.S.: Fructose-fed streptozotocin-injected rat an alternative model for type 2 diabetes. Pharmacological Reports, 64: 129-39, 2012.

9- UNLUCERCI Y., BEKPINER S., GURDOL F. and SEFEROGLU G.: A study on the relationship between homocysteine and diabetic nephropathy in rats. Pharmacol. Res., 45 (3): 249-52, 2002.

10- GOMEZ R., HUBER J., TOMBINI G. and BARROS H.M.T.: Acute effect of different antidepressants on glycemia in diabetic and non-diabetic rats, Braz. J. Med. Biol. Res., 34 (1): 57-64, 2001.

11- CAMELIA C.I., BALTRU D., MAIER M., MURSAN A. and CLICHICI S.: Effects of Quercetin and Chronic (Training) Exercise on Oxidative Stress Status in Animals with Streptozotocin-Induced Diabetes Bulletin UASVM, Veterinary Medicine, 70(1)/2013 Print ISSN 1843-5270; Electronic ISSN 1843-5378, 2013.

12- BÜLBRING E. and CHOU T.C.: The relative activity of prostigmine homologues and other substances as antagonists to tubocurarine. Brit. J. Pharmacol., 2 (1): 8-22, 1947.

13- YIN F.C., SPURGEON H.A., RAKUSAN K., WEISFELDT M.L. and LAKATTA E.G.: Use of tibial length to quantify cardiachypertrophy: Application in the aging rat. Am. J. Physiol., 243 (Heart Circ. Physiol. 12): H941H947, 1982.

14- TRINDER P.: Enzymatic colorimetric method for determination of glucose, cholesterol and triglycerides. Ann. Clin. Bioche., 6: 24-7, 1969. 
15- GONEN E. and RUBENSTEIN A.H.: Diabetologia 15: $1,1978$.

16- JUDZEWITSCH R., PFEIFER M., BEST J., HALTER J. and PORT D.: Chronic chlorpropamide therapy of noninsulin dependent diabetes augments and stimulated insulin secretion by increasing islet sensitivity to glucose. J. Clin. End. and Metab., 55: 321-8, 1982.

17- TAYLOR P.C.: Anti-TNF therapy for rheumatoid arthritis and other inflammatory diseases. Mol. Biotechnol., 19 (2): 153-68, 2001.

18- KORACEVIC D., KORACEVIC G. and DJORDJEVIC V.: Method for the measurement of antioxidant activity in human fluids. J. Clin. Pathol., 54 (5): 356-61, 2001.

19- OHKAWA H., OHISHI W. and ANAL Y.K.: Assay for lipid peroxides in animal tissues by thiobarbituric acid reaction. Anal. Biochem., 95 (2): 351-8, 1979.

20- D'SOUZA D.M., AL-SAJEE D. and HAWKE T.J.: Diabetic myopathy: Impact of diabetes mellitus on skeletal muscle progenitor cells, Front. Physiol., 4: 379, 2013.

21- ANDERSEN H., GJERSTAD M.D. and JAKOBSEN J.: Atrophy of foot muscles: A measure of diabetic neuropathy. Diabetes Care, 27: 2382-5, 2004.

22- PARK S.W., GOODPASTER B.H., LEE J.S., KULLER L.H., BOUDREAU R., De REKENEIRE N., HARRIS T.B., KRITCHEVSKY S., TYLAVSKY F.A., NEVITT M., CHO Y.W. and NEWMAN A.B.: Excessive loss of skeletal muscle mass in older adults with type 2 diabetes. Diabetes Care, 32: 1993-7, 2009.

23- KELLEY D.E. and MANDARINO L.J.: Fuel selection in human skeletal muscle in insulin resistance: A reexamination. Diabetes, 49: 677-83, 2000.

24- BECK-NIELSEN H., PEDERSEN O. and LINDSKOV H.O.: Impaired cellular insulin binding and insulin sensitivity induced by high-fructose feeding in normal subjects. Am. J. Clin. Nutr., 33 (2): 273-8, 1980.
25- LUSTIG R.H.: Fructose: Metabolic, hedonic, and societal parallels with ethanol. J. Am. Diet. Assoc., 110 (9): 130721, 2010.

26- ZOZULINSKA D. and WIERUSZ-WYSOCKA B.: Type 2 diabetes mellitus as inflammatory disease. Diabetes Res. Clin. Pract., 74: S 12-S16, 2006.

27- SAGHIZADEH M., ONG J.M., GARVEY W.T., HENRY R.R. and KERN P.A.: The expression of TNF alpha by human muscle: Relationship to insulin resistance. J. Clin. Invest., 97: 1111-6, 1996.

28- FERNANDEZ-REAL J.M. and PICKUP J.C.: Innate immunity, insulin resistance and type 2 diabetes. Trends. Endocrinol. Metab., 19: 10-6, 2008.

29- BAJAJ S. and KHAN A.: Antioxidants and diabetes. Indian J. Endocrinol. Metab., 16: S267-71, 2012.

30- GAO C., CHEN X., LI J., LI Y., TANG Y., LIU L., CHEN S., YU H., LIU L. and YAO P.: Myocardial mitochondrial oxidative stress and dysfunction in intense exercise: Regulatory effects of quercetin. Eur. J. Appl. Physiol., 114 (4): 695-705, 2014.

31- SANDERS R.A., RAUSCHER F.M. and WATKINS J.B. Effects of quercetin on antioxidant defense in streptozotocin-induced diabetic rats. J. Biochem. Mol. Toxicol., 15: 159-64, 2001.

32- SAAD M.I., KAMEL M.A. and HANAFI M.Y.: Modulation of Adipocytokines Production and Serum NEFA Level by Metformin, Glimepiride, and Sitagliptin in HFD/STZ Diabetic Rats Biochemistry Research International Volume 2015, Article ID 138134, 7 pages.

33- EID H.M., NACHAR A., THONG F., SWEENEY G. and HADDAD P.S.: The molecular basis of the antidiabetic action of quercetin in cultured skeletal muscle cells and hepatocytes; Pharmacognosy Magazine, 11 (41): 74-81, 2015.

34- PROCHAZKOVA D., BOUSOVA I. and WILHELMOVA N.: Antioxidant and prooxidant properties of flavonoids. Fitoterapia, 82: 513-23, 2011.

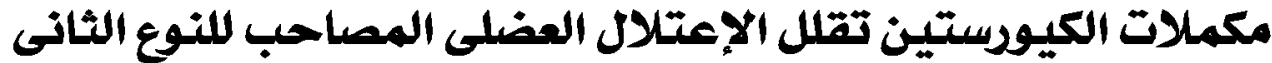

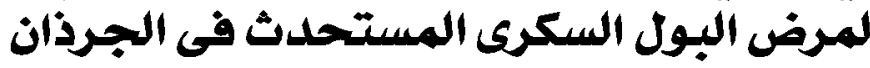

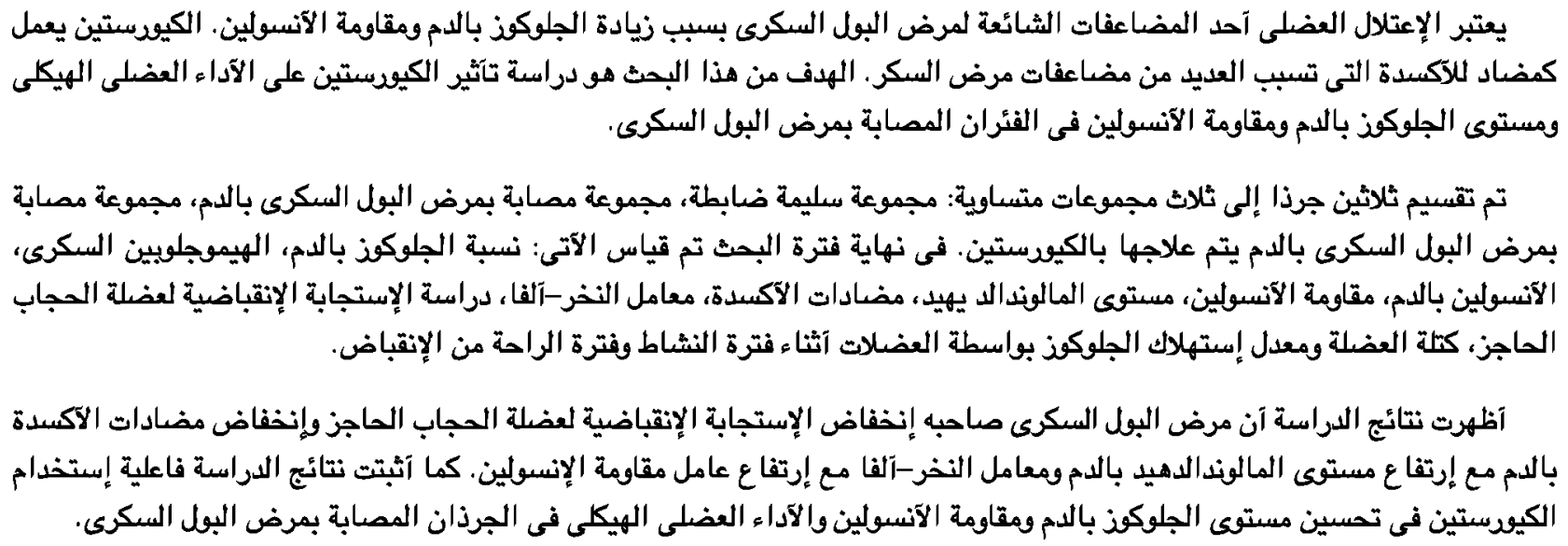

